\title{
ANOTACIONES A LA SILVA "A UNA MINA", DE FRANCISCO DE QUEVEDO
}

El poema de Quevedo "A una mina" es una diatriba contra el que, ansioso de riquezas, arriesga su vida en el mar. Constituye un lugar común de la literatura clásica la idea de que los mares fueron creados para separar las tierras y para que sus habitantes se desconociesen entre sí. La navegación, que no existía en la Edad de Oro, nació, contrariando ese decreto divino, de la codicia de metales preciosos, promoviendo enfrentamientos entre los pueblos y dando lugar, con sus peligros y naufragios, a una nueva causa de muerte. En el poema de Quevedo se unen la censura contra la navegación y la condena a la avidez de riquezas.

El tema es frecuente en poetas moralistas clásicos y cristianos. Tomemos como ejemplo, entre muchos posibles, estas líneas de un sermón de san Agustín donde aparecen, de forma compacta, todos los temas que se despliegan en la silva de Quevedo:

Navigare, inquit alius, et negotiari magnum est; scire multas provincias, lucra undique capere... sempre peregrinari, et diversitate negotiorum et nationum animum pascere, et augmentis lucrorum divitem remeare... Lucra tu quanto stabunt? Quando praesumpturus, quando securus eris ex his quae acquiris? Quanto eris ditior, tanto timidior. Uno naufragio nudus exibis ${ }^{\text {. }}$.

En las páginas que siguen, iré copiando el poema en su totalidad, intercalando mis propios comentarios, en un intento de aclarar el sentido literal del texto y señalar las fuentes y motivos tradicionales

${ }^{1}$ Enarraciones sobre los Salmos, trad. B. Marín Pérez, BAC, Madrid, 1964-1967, t. 4, p. 531. "Navegar, dice otro, y hacer negocios es una cosa grande; conocer muchas provincias, conseguir ganancias por doquier... ir siempre de un lado a otro y apacentarse en la diversidad de los negocios y de las naciones y volver rico con los aumentos de las ganancias... ¿Cuánto durarán tus ganancias? ¿Cuán to tiempo podrás estar confiado, cuanto tiempo estarás seguro de lo que adquieres? Cuan to más rico seas, más inseguro estarás. Saldrás desnudo de un naufragio". 
de que provienen los diversos temas y pasajes. Sigo la edición de J. M. Blecua $^{2}$, salvo en algún punto, que explico. Para los problemas textuales que el poema plantea, es importante el trabajo de M. del Carmen Rocha incluido en Cinco silvas ${ }^{3}$. La silva comienza con estas palabras:

Diste crédito a un pino, a quien, del ocio rudo, avara mano trajo del monte al agua, peregrino, oh Leiva, de la dulce paz tirano.

En estos cuatro versos encontramos tal cantidad de elementos codificados típicos de la poesía del Siglo de Oro que lo más probable es que un lector actual no familiarizado con este lenguaje sea incapaz de comprenderlos correctamente. En efecto, hay al menos cuatro pun tos susceptibles de elucidación: la metonimia de "pino" por "barco", la contraposición entre el árbol enraizado en la tierra y el árbol convertido en tablas y mástiles; la idea de que la navegación, producto de la avaricia y del deseo de riquezas, destruye la paz entre los pueblos, y finalmente, la fórmula según la cual embarcarse es "dar crédito", es decir, confiar la propia vida a algo tan inseguro como una embarcación.

[v. 1] "diste crédito": la expresión "fiarse de" o "confiar en" u otras semejantes, con un complemento que se refiere al barco, se convierte en una acuñación verbal que va unida al motivo de la condena de la navegación. La encontramos en la poesía latina con diversos verbos como committo, credo, fido, confido, siempre con el mismo sentido: "qui fragilem truci / commisit pelago ratem"4; "nec vitam pelago nec ventis credere vota / audebant" potuit tenui fidere ligno"6; "I nunc et ventis animam conmite dolato / confissus ligno"7. Lo mismo vemos en la Biblia: "propter hoc etiam

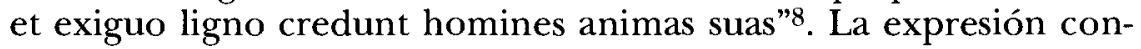
tinúa siendo un elemento canónico del topos de la navegación en la

${ }^{2}$ F. de Quevedo, Obra poética, ed. J. M. Blecua, Castalia, Madrid, 1969, t. 1, núm. 136. En adelante, $O P$, seguido del número.

${ }^{3}$ F. de Quevedo, Cinco silvas, ed. M. del C. Rocha de Sigler, Universidad, Salamanca, 1994, pp. 159-192.

${ }^{4}$ Horacio, Odas, I, III, 10-11. “...que confió al mar feroz una frágil embarcación". Las obras latinas que incluyo en este trabajo las cito siempre por las ediciones de la Loeb Classical Library, salvo que indique lo contrario.

${ }^{5}$ MANiLio, I, 77-78. “...ni se atrevían a confiar la vida al mar ni sus deseos a los vientos".

"SÉNECA, Medea, 305-306. “...y pudo fiarse de un frágil leño cortando las llanuras del mar con dudosa carrera".

${ }^{7}$ JUVENAL, XII, 57-58. "Ve ahora y encomienda tu alma a los vientos, confiado en un madero desbastado".

8 Sabiduría, 14, 6. "...por eso los hombres confian sus vidas a un frágil leño”. 
literatura posterior: "ignotis pelagi vitam committeret undis"9; "Hic ob exiguum, idque incertum lucellum, per omnia maria volitat, undis ac ventis vitam committens, nulla pecunia reparabilem"10; "Non dubitans animam tenui concredere ligno"l1. En la poesía del Siglo de Oro encontramos también múltiples ejemplos: "Ténganse su tesoro / los que de un falso leño se confían"12; "al mar fiando, al viento, / no aromáticos leños, sino alados"13; "que a una Libia de ondas su camino / fió y su vida a un leño"14; "el que fió mil vidas de una lengua / de imán tocada"15; "fió del mar azul el verde pino"16; "Indi al'instabil fè del flutto infido / sestesso crede e si commette al vento"17; "Fatigue la ambición de los mortales / el ancho reino, procurando el oro, / fiada de una tabla en la defensa"18; "Preñada de tributos de occidente, / nave soberbia, al agua te fiaste"19; "del mar fiando el oro y el diamante..." ( $O P$, núm. 134); "El que fiare sus velas / a tiempos de tan mal tiempo / saldrá de la mar a fuerza / de remos y de escarmientos"20; "Quien osado fió su vida al viento, / del mar rompiendo intrépido el camino"21; "De muchos pues el rey acompañado, / dos veces diez galeras fió al viento"22. La expresión aparece también en textos en prosa: "Acabé de confirmar por insensatos a los hombres que... ponen sus vidas en la confianza de una débil tabla"23; "el primero que con escandalosa temeridad fió su vida en un frágil leño al inconstante elemento"24.

${ }^{9} \mathrm{~J}$. Sannazaro, The piscatory eclogues, ed. W. P. Mustard, The Johns Hopkins Press, Baltimore, 1984, III, 16. "...confiaron la vida a las ignotas ondas del mar".

${ }^{10}$ Erasmo de Rotterdam, Elogio de la locura, ed. O. Nortes Villas, Bosch, Barcelona, 1991 , cap. 48 , p. 228. "Aquel, para ganar un lucro exiguo e incierto, revolotea por todos los mares, confiando a las olas y a los vientos la vida, que ninguna riqueza podrá reparar".

${ }^{11}$ Juan Segundo, "Elegías", Besos y otros poemas, ed. O. Gete Carpio, Bosch, Barcelona, 1979, VII, v. 79. “...no vacilando en confiar su vida a un débil leño”.

12 Fray Luis de León, Poesía, ed. J. F. Alcina, Cátedra, Madrid, 1986, p. 73. p. 116.

13 Luis de Góngora, Sonetos, ed. B. Ciplijauskaité, Castalia, Madrid, 1978,

14 L. De Góngora, Soledades, ed. R. Jammes, Castalia, Madrid, 1994, 1, $20-21$.

${ }^{15}$ FÉlix Lope de Vega, Rimas, ed. F. Pedraza, Universidad de Castilla-La Mancha, 1993-1994, t. 1, p. 245.

16 Valdivielso, Vida de San Josef, Atlas, Madrid, 1948, BAE, t. 29, p. 148.

17 G. B. Marino, 'Adone, ed. G. Pozzi, Adelphi, Milano, 1988, 1, 56.

18 Príncipe de Esquilache, Obras en verso, Amberes, 1654, p. 54.

19 Salas Barbadillo, en Ramón Andrés, Tiempo y caída, Sirmio, Barcelona, 1994, p. 800 .

20 Antonio Hurtado de Mendoza, Obras poéticas, ed. R. Benítez Claros, Real Academia Española, Madrid, 1947, t. 2, p. 244.

${ }^{21}$ Juan de Moncayo, Rimas, ed. A. Egido, Espasa-Calpe, Madrid, 1976, p. 81.

${ }^{22}$ Francisco de Trillo y Figueroa, Obras, ed. A. Gallego Morell, CSIC, Madrid, 1951 , p. 548.

${ }_{23}$ Vida y hechos de Estebanillo González, ed. A. Zamora Vicente, Noguer, Barcelona, 1976 , t. 2, p. 242.

${ }^{24}$ Baltasar Gracián, El Criticón, ed. M. Romera-Navarro, University of Pennsylvania Press, 1938, t. 1, p. 105. 
[v. 1] "a un pino": en la poesía latina es una metonimia frecuente por "barco": "nec nautica pinus / mutabit merces"25; Horacio, dirigiéndose a una nave, dice: "Quamvis Pontica pinus, / silvae filia nobilis, / iactes..."26; "Nondum... / in liquidas pinus descenderat undas"27; "Nondum caeruleas pinus contempserat undas"28; "pinus / dicuntur liquidas Neptuni nasse per undas"29; "Bene dissaepti foedera mundi / traxit in unum Thessala pinus" 30 . Lo mismo sucede en la poesía del Siglo de Oro: Góngora explica que el primer navegante "surcó, labrador fiero, / el campo undoso en mal nacido pino" 31 ; cf. también: "te fiaste con un frágil pino / de tentar el furor del viento airado"32; "abriendo sendas por sus ondas graves / los hijos de los montes, / excelsos pinos y labradas hayas"33; "Fías... en alado pino / los tesoros al mar"34.

[v. 2] Blecua edita este verso así: "a quien del ocio dura avara mano", frase que sólo se puede interpretar como: "a quien la dura y avara mano del ocio trasladó del monte, donde vivía el árbol, al mar, para convertirlo en navio"; pero no se entiende por qué es "la mano del ocio" la que realiza esta acción. M. del Carmen Rocha ofrece, basándose en testimonios más numerosos y fehacientes, esta otra versión: "a quien del ocio rudo, avara mano", con lo que la idea sería: "una mano avara trajo el pino hasta el mar, sustrayéndolo al ocio rudo en que se hallaba cuando estaba en el monte". La presencia de dos complementos de lugar formalmente tan parecidos como "del ocio rudo" y "del monte", que resulta un tanto incómoda, puede ser un obstáculo con tra esta hipótesis; en todo caso, la sintaxis de la frase disimula con bastante éxito ese paralelismo.

Es tradicional la idea de que los barcos fueron un invento pernicioso, y que la navegación es fruto de la avaricia y del deseo de riqueza. Por eso la mano que transformó el pino en nave es "avara". El tema aparece en diversos poetas latinos: "Quaerat avarus opes et, quae lassarit

${ }^{25}$ Vrrgilio, Bucólicas, IV, 38-39. “...niel pino naveganteintercambiarámercancías”.

26 Odas, I, XIV, 11-13. "Aunque te envanezcas de ser pino del Ponto, hija de noble bosque".

27 Ovioro, Metamorfosis, 1, 94-95. "Todavía el pino no había descendido a las líquidas ondas".

28 Tibulo, 1, 3, 37. "Todavía el pino no había desafiado a las ondas azules".

29 Catulo, LXIV, 1-3. "...se dice que unos pinos nadaron por las líquidas ondas de Neptuno".

${ }^{30}$ SÉNECA, Medea, vv. 335-336. "Las tierras bien separadas por las leyes del mundo las unió un pino de Tesalia".

31 Soledades, I, w. 370-371.

32 C. DE VIRuÉs, Historia del Montserrate, Atlas, Madrid, 1945, BAE, t. 17, p. 525.

33 LOPE DE VEGA, "El siglo de oro", Rimas humanas y otros versos, ed. A. Carreño, Crítica, Barcelona, 1998, p. 795.

${ }^{34} O P$, núm. 115. Cf. RaFaEl LAPESA, Poetas y prosistas de ayer y de hoy, Gredos, Madrid, 1977, pp. 115 ss. 
arando, / aequora periuro naufragus ore bibat" 35 ; "Natura insidians pontum substravit avarus" 36 . La idea se halla también en la Biblia: "Pues ésta [la nave] fue inventada por la codicia de lucro" (Sabiduría, 14, 2). Pedro Díaz de Rivas, en sus anotaciones a la "Canción de la toma de Larache" de Góngora, comentando el verso "piloto el interés sus cables ata", dice: "Es cosa común a los autores decir que la cudicia fue causa de intentar las navegaciones... De aquí nacieron muchas odas y canciones de poetas vulgares a la cudicia de los navegantes" 37 .

[v. 3] "trajo del monte al agua": en la poesía clásica es muy frecuente que se recuerde la procedencia de la madera con la que se ha construido el barco, y se trace una relación entre el árbol, antes de ser cortado, y la nave que con él se fabricó, contraponiendo la paz primera a los peligros de la navegación. Así lo vemos en los primeros versos de la Medea de Eurípides: “Ojalá la nave de Argos no hubiera volado sobre las sombrías Simplégades hacia la tierra de Cólquide, ni en los valles del Pelión hubiera caído el pino cortado por el hacha, ni hubiera provisto de remos las manos de los valerosos hombres que fueron a buscar para Pelias el vellocino de oro!". Ovidio, hablando de la Edad de Oro, en la que aún no se habían inventado los barcos, dice en un verso, ya citado ( supra, p. 574), que "Ningún pino... había descendido aún de sus montañas a las límpidas aguas”, y luego caracteriza a la Edad de Hierro porque "quaeque prius steterant in montibus altis, / fluctibus ignotis exsultavere carinae"38. Esta contraposición aparece también en la poesía del Siglo de Oro: "El verde robre, que es barquillo ahora" 39 ; "Hija de noble selva -cual presume / tu nave altiva y fuerte-fue la mía” 40 ; “ ¿Dónde vas, ignorante navecilla, / que, olvidando que fuiste un tiempo haya, / aborreces la arena de esta orilla, / donde te vio con ramos esta playa?" ( $O P$, núm. 138, vv. 1-4); "ausente yace de la selva cara, / do el verde ornato conservar pudiera" 41 ; "Este que ves, oh huésped, vasto pino, / útil sólo a la llama ya en el puerto, / selva frondosa un tiempo, en descubierto / cielo dio amiga sombra al peregrino" 42 ; "lo que es leño en la mar, es

35 Ovidio, Amores, II, X, 33-34. "Busque el avaro riquezas y, náufrago, beba con su boca perjura las olas que ha fatigado el surco de su barco".

${ }^{36}$ Propercio, III, 7, 37. "La naturaleza tendió a los avaros asechanzas en el mar".

37 Eunice J. Gates, "Anotaciones a la Canción de la toma de Larache por Pedro Díaz de Rivas", $R F E, 44$ (1961), p. 86.

38 Metamorfosis, I, 94 y 133-135. "...y las quillas que antaño se habían erguido en las altas montañas saltaron a las olas desconocidas”.

39 Soledades, II, v. 38.

${ }^{40}$ Luis Car rillo de Sotomayor, Poesías completas, ed. D. Alonso, Signo, Madrid, 1936, p. 105.

${ }^{41}$ Juan de Jáuregui, Obras, ed. I. Ferrer, Espasa-Calpe, Madrid, 1973, t. 1, p. 30.

42 Francisco de Rioja, Poesía, ed. B. López Bueno, Cátedra, Madrid, 1984, p. 159 ; cf. también pp. 172 y 219. 
aquí haya"43; "De selva nieto fue, para ser hijo / de artífice prolijo, / bajel que ya cascado / se queja" 44 .

[v. 3] "peregrino": aplicado al árbol, significa que, a pesar de ser por naturaleza un objeto arraigado al suelo, fue trasladado desde su lugar hasta las aguas. El término procede sin duda de Ovidio, que emplea la misma palabra en un contexto semejante: "nondum caesa suis, peregrinum ut viseret orbem, / montibus in liquidas pinus descenderat undas" 45 . Lo que ocurre es que en Ovidio, "peregrinum" concierta con "orbem", es decir, que se refiere a "un mundo lejano, extraño", mientras que en Quevedo, "peregrino" se refiere sin duda a "pino". $\mathrm{El}$ sentido es muy diferente, pero la semejanza temática y de vocabulario nos lleva a pensar, de todos modos, en que hay una referencia clara y deliberada al texto de Ovidio, tanto más cuanto que lo que hemos visto en Quevedo ocurre en otros poetas anteriores. Así, Tasso, hablando también de la Edad de Oro, dice: "né portó peregrino / o guerra o merce agli altrui lidi il pino" 46 , donde "peregrino" se refiere igualmente a "pino". Es curioso observar que Juan de Jáuregui traduce estos versos atendiendo más a la procedencia ovidiana que a la letra de Tasso: "ni llevó nave a la extranjera tierra / la vil cudicia o la sangrienta guerra" 47 . En II pastor fido de Guarini hay una frase que tiene que venir del mismo origen: "ond'é che il peregrino / va l'altrui terra e'l mar turbando il pino" 48 . También Guarini está hablando de la Edad de Oro y su texto es una imitación muy clara del de Tasso. Ocurre, sin embargo, que lo que él dice literalmente es que "el peregrino va a tierras ajenas y el pino va turbando el mar", frase que ha causado cierta perplejidad entre los editores de $I l$ pastor fido. Es tentador imaginar que lo que escribió realmente Guarini fue: "ond'é che, peregrino, / va l'altrui terra e'l mar turbando il pino”, que creo que tendría más sentido.

[v. 4] No está claro a quién se aplica la frase "tirano de la dulce paz". Podría ser al destinatario, que al embarcarse destruye su propia paz, o bien al pino mismo que, transformado en barco, se convierte en fuente de angustias e inquietudes o incluso que, al poner en comunicación a pueblos que se desconocían, da origen a las guerras. La palabra "tira-

43 Pedro de Espinosa, Poesias completas, ed. F. López Estrada, Espasa-Calpe, Madrid, 1975, p. 145.

44 Esteban Manuel de Villegas, Eróticas o amatorias, ed. N. Alonso Cortés, Espasa-Calpe, Madrid, 1969, p. 25.

${ }^{45}$ Metamorfosis, 94-95. "El pino, cortado de sus montes, aún no habia descendido a las líquidas ondas para conocer mundos lejanos".

${ }^{46}$ Torquato Tasso, Aminta, en Opere, ed. B. Maier, Rizzoli, Milano, 1963, t. 1, p. 124.

${ }^{47} \mathrm{~J}$. DE JÁuregui, Obras, t. 2, p. 110.

48 Battista Guarini, Ilpastorfido, ed. M. Guglielminetti, Tea, Milano, 1994, p. 247. 
no" está usada en un modo muy frecuente en Quevedo, con el sentido de "opresor" o "destructor", pero fuera de toda denotación política.

El nombre del destinatario es Leiva (o Loiva según otros testimonios). Tan to Crosby como M. del Carmen Rocha ${ }^{49}$ han barajado algunas hipótesis para identificar a este personaje. El apellido Leiva, tan diferente de los nombres arcaicos y emblemáticos como Licino, Licas, Fabio o Clito que aparecen en otros poemas de Quevedo, hace suponer que se trata de una persona real y no de un interlocutor ficticio.

$5 \quad$ Viste, amigo, tu vida por tu codicia a tanto mal rendida.

Arrojote violento adonde quiso el albedrío del viento. ¿Qué condición del Euro y Noto ignoras?

10 ¿Qué mudanzas no sabes de las horas? Vives, y no sé bien si despreciado del agua, o perdonado.

En estos versos, hasta el v. 21, el poeta habla de los peligros marítimos a que se arriesgó el interlocutor del poema arrastrado por su ambición.

[v. 9] El Euro y el Noto aparecen juntos en un verso de Virgilio: "Eurusque Notusque ruunt" 50 . La pregunta retórica supone que no ignora ninguna, es decir, que ha sufrido todos los peligros ocasionados por estos vientos en las tempestades marinas.

[v. 10] “¿Qué mudanzas no sabes de las horas?”: sabes que a cada momento cambian las circunstancias y la suerte del hombre.

¡Cuántas veces los peces que el mar cierra y tuviste en la tierra

15 por sustento, en la nave mal segura, les llegaste a temer por sepultura!

¿Qué tierra tan extraña no te obligó a besar del mar la saña? ¿Cuál alarbe, cuál scita, turco o moro, mientras al viento y agua obedecías, por señor no temías?

[vv. 13-16] El temor del navegante a acabar siendo alimento de los peces es una tema que aparece en la Antología griega y en Ovidio: "et

${ }^{49}$ J. O. Cros By, En torno a la poesía de Quevedo, Castalia, Madrid, 1967, p. 161 y M. del C. Rocha, ed. cit. a Cinco sitvas, p. 185.

${ }^{50}$ Eneida, I, 85. 
non aequoreis piscibus esse cibum"51. La idea de que así sustentaría a aquellos que fueron sustento propio se encuentra en Luciano de Samosata: "En una ocasión que se disponía a zarpar en pleno invierno, su amigo le objetó: "¿No temes que naufrague la embarcación y te devoren los peces?» «Sería un ingrato-replicó-si temiese ser comido por los peces, yo, que he comido tantos de ellos»"52. Luego encontramos la idea en algunos poetas de los siglos xvI y xvII: "Porque de mi te vás, ó filho caro, / A fazer o funéreo enterramento / Onde sejas de pexes mantimento?"53; "mas ar corruto, / que neste meu terreno vas tinha, / Me fêz manjar de peixes en ti, bruto / mar"54; "y ser hechos manjar de los pescados / entre arenosas sirtes anegados"55; "Tome ejemplo en mi mal quien no desea / ser cual yo pasto de nadantes mudos"56. "que quizás serás pasto / de los peces que ocupan el mar vasto" 57 . Cf. también $O P$, núm. 134, v. 11.

[vv. 17-18] "La saña del mar te obligó a besar las tierras más extrañas y apartadas". El verbo "besar" puede significar solamente "tocar", como en "En tablas dividida rica nave / besó la playa miserablemente" 58 , o bien puede referirse al hecho de que el náufrago besa la playa como muestra de agradecimiento por su salvación: "Embestimos en la arena, salimos a tierra, besamos el suelo" 59 o en Soledades, cuando el náufrago "besa la arena" $(I, 29)$. A veces el sentido puede mantenerse en una ambigua zona intermedia: " $y$ bien dichoso, si alguna haya / rota concede beses esta playa!"60.

[vv. 19-21] El naufragio le hubiera podido llevar a tierras enemigas donde sería convertido en esclavo. "Alarbe": "Vale tanto como hombre bárbaro, rudo, áspero, bestial, o sumamente ignorante. Dícese por comparación a la brutalidad y fiereza que se experimentó en los árabes o alárabes que poseyeron España" (Dicc. Aut.). Gonzalo Correas registra como frase proverbial "hecho un alárabe" con el signilas aguas".

51 VII, ep. 273,274 y 288 y Tristes, I, 2, v. 56 . “...y no ser alimento de los peces de

52 "Vida de Demonacte", 35, en Obras, trad. A. Espinosa Alarcón, Gredos, Madrid, 1997, t. 1, pp. 137-138. IV, 90.

53 Luıs de Camões, Os Lusiadas, ed. A. José Saraiva, Figueirinhas, Oporto, 1978 ,

54 L. DE CAmões, Lirica, eds. J. M. Rodríguez y A. Lopez Vieira, Coimbra, 1932, son. 190 .

55 Diego Ramírez Pagán, Floresta de varia poesia, ed. A. Pérez Gómez, Selecciones Bibliófilas, Barcelona, 1950, 1, p. 94.

56 F. DE RIOJA, Poesia, p. 157.

57 E. M. DE VILLEGAS, Eróticas o amatorias, p. 83.

58 Luis de Gõngora, Fábula de Polifemo y Galatea, ed. D. Alonso, Gredos, Madrid, 1967, vv. 433-434.

59 Miguel de Cervantes, El Quijote, ed. F. Rico, Crítica, Barcelona, 1998, 1, cap. 41, p. 462.

${ }^{60}$ L. Carrillo Sotomayor, Poesias completas, p. 106. 
ficado de "cruel"61. En un poema de Liñán de Riaza se dice: "Fuese a correr las fronteras / por gran capitán de alarbes: / de alarbes había de ser, / pues que se atrevió a dejarte"62. Los escitas aparecen con frecuencia en la literatura como ejemplo de crueldad y fiereza.

Mucho te debe el oro

si, después que saliste, pobre reliquia, del naufragio triste,

25 en vez de descansar, del mar seguro, a tu codicia hidrópica obediente, con villano azadón, del cerro duro sangras las venas del metal luciente. ¿Por qué permites que trabajo infame

30 sudor tuyo derrame?

Deja oficio bestial que inclina al suelo ojos nacidos para ver el cielo.

[v. 22] "Mucho te debe el oro": el oro tiene mucho que agradecerte por el amor que le tienes. Cf. "Mucho le debes, fuente, a la verbena, / que sola te acompaña" ( $O P$, núm. 400, vv. 30-31). La construcción en la que el verbo "deber" tiene un sujeto inanimado y un complemento de orden cuantitativo resulta especialmente literaria. Cuervo, en su Diccionario de régimen, aduce este ejemplo de fray Luis: "Mas a los que dicen que no leen aquestos mis libros por estar en romance, y que en latín los leyeran, se les responde que les debe poco su lengua, pues por ella aborrecen lo que si estuviera en otra tuvieran por bueno"63.

[v. 25] Añado una coma después de "descansar", pues "seguro" no califica a "mar", sino que se aplica al interlocutor del poema, el cual estará "seguro de los peligros del mar".

[v. 26] "obediente a tu codicia hidrópica": en el lenguaje literario, es muy frecuente la comparación de la hidropesía con la codicia, hasta el punto de que tanto Sebastián de Covarrubias como el Dicc. Aut. lo dan como una segunda acepción: "traslaticiamente se toma como deseo desordenado de riquezas" 64 . Cf.: "Crescit indulgens sibi dirus hydrops"65; "Quem currus inflatum vehit / Hydrops aquosus lucido /

61 Vocabulario de refranes y frases proverbiales, eds. L. Combet, R. Jammes y M. MirAndreu, Castalia, Madrid, 2000, p. 940.

62 Pedroliñán de Riaza, Poesias, ed.J. F. Randolph, Puvill, Barcelona, 1982, p. 276.

${ }^{63}$ Fray Luis de León, De los nombres de Cristo, ed. F. de Onís, Espasa-Calpe, Madrid, 1969, t. 3, p. 10.

64 Diccionario de Autoridades, ed. facs., Credos, Madrid, 1984; véase también S. de Covarrubias, Tesoro de la lengua castellana o española, ed. M. de Riquer, Alta Fulla, Barcelona, 1987.

${ }^{65}$ Horacio, Odas, II, II, 13. “...se hincha el hidrópico funestamente indulgente consigo mismo". 
Tendit veneno intrinsecus" 66 ; "Aqueles que estáo co'a boca aberta, / Por se encher de tesouros, de hora em hora, / Doentes desta falsa hidropesia" 67 ; "Sedienta bestia, hidrópica, hinchada, / principio y fin de todos nuestros males, / oh insaciable codicia de mortales" 68 ; "y que acusen mi avara hidropesía" ( $O P$, núm. 44); "pálida sed hidrópica del oro" ( $O P$, núm. 88). También Quevedo habla, refiriéndose a san Pablo antes de su conversión, de "aquella hidropesía de san gre de los cristianos"69. Otras veces la hidropesía es metáfora de la ambición de cargos y de honores: "No en ti la Ambición mora / hidrópica de viento"70; de los deseos mundanos: "Ignorante ella de los eternos bienes, hidrópica de sus gustos perecederos"71; o del anhelo amoroso: "Cuanto más bebe queda más sediento, / que es el amor mortal hidropesía"72; "ojos hidrópicos creo / que mis ojos deben ser"73. Cf. más ejemplos en la edición de La vida es sueño de E. Rull y en la de $E l$ desdén, con el desdén, de Francisco Rico ${ }^{74}$.

\section{[v. 27] "con villanoazadón": villano porque es instrumento de labranza.}

[v. 28] Hay un juego de palabras con la palabra "venas" que aquí significa las vetas o filones del mineral pero que a su vez son "sangradas" como las venas del cuerpo. En el "Sermón estoico de censura moral" se dice, hablando de la minería, que el hombre rompió los senos de la tierra, "despedazole el pecho, / rompióle las entrañas, / desangróle las venas" (vv. 145, 112-114). Compárese: "que hoy a España tributa y da barata / la sangre de sus venas vuelta en plata"75.

[vv. 31-32] Los moralistas y poetas clásicos señalan que la posición erguida del hombre, frente a la de los animales, es expresión de su nobleza espiritual y de su destino ultraterreno. La idea se encuentra en

66 Prudencio, Peristeph, Obras completas, trads. A. e I. Ortega Rodríguez, BAC, Madrid, 1981, Hym. 2, w. 238-240. "Al que, engreído, transporta una carroza, la enaguazada hidropesía por dentro le hincha con su pálido veneno".

${ }^{67}$ L. DE Camóes, "Ao desconcerto do mundo", Lirica, p. 282.

${ }^{68}$ Alonso de Ercilla, La Araucana, ed. I. Lerner, Cátedra, Madrid, 1993, III, 1 , p. 135.

${ }^{69}$ Francisco de Quevedo, La caida para levantarse, ed. V. Nider, Giardini, Pisa, 1994, p. 163.

${ }^{70}$ Góngora, Soledades, I, 108-110.

${ }^{71}$ Baltasar Gracián, El Comulgatorio, eds. M. Batllori, A. Egido y L. Sánchez Laílla, Larrumbe, Zaragoza, 2003, p. 67.

72 Bernardo de Balbuena, El Bernardo, Atlas, Madrid, 1945, BAE, t. 17, IV, p. 181 .

${ }^{73}$ Pedro Calderón de la Barca, La vida es sueño, ed. E. Rull, Alhambra, Madrid, 1980, vv. 227-228.

${ }^{74}$ Ed. cit. supra, n. 73 y Agustín Moreto, El desdén, con el desdén, ed. F. Rico, Castalia, Madrid, 1971, p. 147.

75 B. DE Balbuena, El Bernardo, p. 331. 
Platón ${ }^{76}$ y también en Aristóteles ${ }^{77}$, pero el tópico adquiere su expresión genuina en Cicerón: "quae primum eos humo excitatos celsos et erectos constituit, ut deorum cognitionem caelum intuentes capere possent. Sunt enim ex terra homines non ut incolae atque habitatores, sed quasi spectatores superarum rerum atque caelestium, quarum spectaculum ad nullum aliud genus animantium pertinet"78. "Nam cum ceteras animantes abiecisset ad pastum, solum hominum erexit et ad caeli quasi cognationis domiciliique pristini conspectum excitavit"79. La idea aparece en varios poetas latinos: "Pronaeque cum spectent animalia cetera terram, / os homini sublime dedit caelumque videre / iussit et erectos ad sidera tollere vultus" 80 ; "stetis unum in arcem / erectus capitis victorque ad sidera mittit / sidereos oculos propiusque aspectat Olympum / inquiritque Iovem" 81 ; "Nonne vides, hominum ut celsos ad sidera vultus / sustulerit deus ac sublimi finxerit ora, / cum pecudes volucrumque genus formasque ferarum / segnem atque obscenam passim stravisset in alvum?" 82 ; "O curvae in terris animae et caelestium inanis" 83 ; de estos versos de Juvenal provienen dos famosas imitaciones en la poesía del siglo xvix: "Levate il guardo al vostro albergo eterno, / anime curve, e'n quest'Abisso immerse, / che nome ha Mondo..." 84 y " $\mathrm{O}$ Oh corvas almas, oh facinorosos / espíritus furiosos!" ( $O P$, núm. 145, vv. 1-2). "In inferiora vero ac terrena degenerans, fragilitatem corporum caducorum deprehedit meram

76 Timeo, 90, ab, p. 258.

77 Partes de los animales, II, 656a 12, p. 111

78 Cicerón, De natura deorum, II, LVI. "Ella [la Naturaleza] nos ha hecho de una figura erguida y derecha, que nos eleva de la tierra para que podamos contemplar el cielo y deducir de él el conocimiento de los dioses. En efecto, los hombres se relacionan con la tierra menos como habitantes o moradores que como espectadores de las cosas superiores y celestes, cuya contemplación no pertenece a ninguna otra especie de vivientes".

79 Cicerón, De legibus, I, IX. "Pues mientras a los otros animales los ha curvado hacia la tierra para que busquen su alimento, al hombre sólo lo hizo erguido hacia el cielo, como si lo animara con la imagen de su parentesco y de su primitiva morada".

80 Ovidio, Metamorfosis, I, 83-85. "Mientras los demás animales están naturalmente inclinados mirando a la tierra, dio al hombre un rostro levantado disponiendo que mirase al cielo y que llevase el semblante erguido hacia las estrellas".

${ }^{81}$ Manilio, IV, 905-908. El hombre "fue el único [entre los animales] en ponerse en pie levantando la cindadela de la cabeza y en su victoria dirigió sus celestes ojos hacia las estrellas, mirando más de cerca el Olimpo e investigando la naturaleza de Júpiter" (v. 907).

82 Silio ITÁlico, XV, w. 84-87. “¿Ignoras que si los dioses han querido que el hombre tuviera la cabeza derecha y elevada, es para que tuviera siempre los ojos fijos en las moradas celestes, mientras que los otros animales, sea cual sea su naturaleza y su forma, curvados hacia la tierra, se arrastran por ella para satisfacer sus apetitos groseros?".

83 Persio, II, 61. "Oh almas encorvadas hacia la tierra y desinteresadas de la cosas celestiales".

${ }^{84}$ G. B. Marino, La Galeria, ed. M. Pieri, Liviana, Padua, 1979, p. 143. 
divinitatem mentis sustinere non posse, immo partem eius vix solis humanis corporibus convenire, quia et sola videntur erecta, tamquam ad supera ab imis recedant, et sola caelum facile, tamquam semper erecta, suspiciunt" 85 .

Esta idea se convierte en motivo de predicación religiosa en los Padres de la Iglesia: "Rectum te Deus fecit, et cum cetera animalia prona et ad terram situ vergente depressa sint, tibi sublimis status et ad coelum adque ad Dominum susum vultus erectus est"86; "Dios extendió los cielos y encendió el sol para levantar a lo alto nuestras miradas; tú, empero, te obligas a ti mismo a mirar hacia abajo, como los cerdos, y obedeces en eso al diablo" 87 ; "Non enim ut animalia rationis expertia prona esse videmus in terram, ita creatus est homo: sed erecta in caelum corporis forma admonet eum quae sursum sunt sapere"88; "Unica gens hominum celsum levat altius cacumen, / atque levis recto stat corpore despicitque terras. / Haec nisi terrenus male desipis, ammonet figura, / qui recto caelum vultu petis exserisque frontem / in sublime feras animum quoque" 89 .

La idea se convierte en un lugar común en la literatura doctrinal de Renacimiento y el Barroco: "Dios... al hombre sólo lo crió y puso mirando a los cielos, el rostro alto, el cuerpo derecho y levantado... $\mathrm{Y}$, cierto, nuestra postura nos muestra no ser nosotros desta tierra naturales, sino criados para imitar y contemplar las cosas altas y celestiales"90. "Cosí el Fabro primier la fronte e gli occhi / alzó de l'uomo a

${ }^{85}$ MaCrobIo, In Somnium Scipionis, ed. M. Armisen-Marchetti, Les Belles Lettres, Paris, 2001-2003, t. 1, 14, 9. "Pero degenerando para llegar a las regiones inferiores y terrestres, el Alma constata que la fragilidad de los cuerpos efímeros no puede soportar la divinidad completamente pura de la inteligencia; esta inteligencia, incluso parcial, conviene sólo a los cuerpos humanos porque se les ve dotados de la postura erguida, como para apartarse en cierto modo de los objetos bajos y tender a los de arriba, porque sólo ellos alzan fácilmente su mirada hacia el cielo, pues siempre están de pie".

86 San Crpriano, "Ad Demetrianum", Obras, trad.J. Campos, BAC, Madrid, 1964, p. 286. "Dios te ha hecho erecto y, así como los demás animales fueron creados con posición inclinada hacia la tierra, a ti, en cambio, te otorgó un rostro vuelto hacia arriba y mirando al cielo y al Señor".

87 San Juan Crisóstomo, Homilias sobre el evangelio de san Mateo, trad. D. Ruiz Bueno, $B A C$, Madrid, 1955, t. 2, p. 66.

88 San Agustín, La ciudad de Dios, trads. S. Santamarta y M. Fuertes, BAC, Madrid, 2001, XXII, 24, 4, p. 927. "Pues el hombre no fue creado como los animales privados de razón, a los que vemos inclinados hacia la tierra; sino que su forma corporal levantada hacia el cielo le advierte de que debe tender hacia las cosas de arriba".

89 Boecio, La consolación de la filosofia, trad. fray A. de Aguayo, Espasa-Calpe, Buenos Aires, 1946, V, 5, 10-14. "Sólo el linaje humano eleva hacia lo alto la cumbre erguida y, ligera, va derecha y desprecia la tierra. Esta figura te advierte, si por tu naturaleza terrena no te extravías: tú que con rostro erguido miras al cielo y alzas la frente, eleva también el ánimo hacia lo alto".

${ }^{90}$ Pedro Mexía, Silva de varia lección, ed. A. Castro, Cátedra, Madrid, 1989 y 1990 , t. 1, p. 328 . 
le stellanti spere, / perchè là guardi, onde celeste origo / ebbe l'alma immortai, ch'eterno regno / par che chiede per grazia al Padre Eterno"91; el propio Tasso vuelve sobre esa idea en su obra en prosa: "Iddio... ordinò dunque che tutti gli animali guidati da la natura seguissero necessariamente gli appetiti del senso; ma non consenti che potessero inalzar gli occhi verso le stelle, accioché non s'invaghissero de le bellezze del cielo, le quali non dovean possedere"92; fray Luis de Granada, en la Introducción al símbolo de la fe, comenta la frase de Cicerón citada más arriba ${ }^{93}$. También encontramos esta idea en la poesía y la prosa del siglo xvir: "Enseña la moral filosofía / que el hombre que jamás del bajo suelo / al cielo levantó la fantasía, / viviendo en pie para mirar el cielo, / es fiera..." "94; "Fue el hombre-dijo Artemiacriado para el cielo y así crece hacia allá; y en esa material rectitud del cuerpo está simbolizada la del ánimo"95.

Séneca, que parece ser la fuente fundamental de estos versos de Quevedo, une este tema con la condena de la minería: "Quae tanta necessitas hominem ad sidera erectum incurvavit et defodit et in fundum telluris intimae mersit, ut erueret aurum?"96.

¿Qué te han hecho, mortal, de estas montañas las escondidas y ásperas entrañas?

¿Qué fatigas la tierra?

Deja en paz los secretos de la sierra a quien defiende apenas su hondura.

¿No ves que a un mismo tiempo estás abriendo

al metal puerta, a ti la sepultura?

¿Piensas, y es un engaño vergonzoso, que le hurtas riqueza al indio suelo? ¿Oro llamas al que es dulce desvelo y peligro precioso, rubia tierra, pobreza disfrazada y ponzoña dorada?

[v. 35] “¿Qué fatigas la tierra?". La interrogación tiene un sentido final: “¿Para qué fatigas la tierra?”. M. del Carmen Rocha interpreta "fatigar" como cultismo con el sentido de "recorrer con insistencia" 97 ,

${ }^{91}$ Torquato Tasso, Il mondo creato, ed. G. Petrocchi, Felice Le Monnier, Firenze, 1951, VII, 511-515.

${ }_{92}$ T. TAsso, "Il messaggiero", Dialoghi, ed. B. Basile, Mursia, Milano, 1991, p. 78.

${ }^{93}$ Ed. J. M. Balcells, Cátedra, Madrid, 1989, p. 463, con nota del editor donde señala otros precedentes. p. 956

${ }^{44}$ FÉLIX Lope De VEGA, Obras poéticas, ed.J. M. Blecua, Planeta, Barcelona, 1983,

95 B. GRACiÁn, El Criticón, I, IX, p. 266-267.

96 SÉnecA, Cuestiones naturales, V, 15, 4. “¿Qué necesidad tan acuciante curvó, hundió y sumergió en las profundidades más recónditas de la tierra al hombre erguido hacia las estrellas con tal de arrancar el oro?".

97 Cinco silvas, ed. cit., p. 171. 
tal como lo emplea Garcilaso ("andes a caza, el monte fatigando"), fray Luis ("En vano el mar fatiga / la vela portuguesa") y Góngora ("peinar el viento, fatigar la selva") y cuyo origen se halla en Eneida IX, 605 ("venatu invigilant pueri silvasque fatigant"). Lapesa, comentando el verso citado de Góngora, analiza los diversos usos y procedencias del cultismo, y dice: "En la acepción de pisar u hollar... se convierte muy pronto en una expresión típica de la lengua poética de Quevedo"98, y pone como ejemplo "pocas pisadas de mortales plantas / fatigan esta arena" ( $O P$, núm. 400, vv. 28-29) y "vio, fatigada, / el alto Pirineo, de gente osada, / la nieve, ceño cano de su frente" (núm. 257), además del verso que estamos comentando. Pero si en los dos primeros ejemplos la explicación parece pertinente, hay que observar que en la frase "¿Qué fatigas la tierra?" no se habla de recorrerla, sino de excavarla. Se trata pues de un uso normal de "fatigar" en el sentido que da el Dicc. Aut. de "acosar, cansar, oprimir, congojar".

[vv. 38-39] El que cava lo hace para "abrir puerta al metal", es decir, para extraer oro de la mina, sin darse cuenta de que, al mismo tiempo, está abriendo su propia sepultura, pues la riqueza no trae más que males y lleva a su poseedor hacia la destrucción.

[v. 41] "al indio suelo": se refiere, naturalmente, a América, a las Indias Occidentales (cf. v. 55)

[vv. 42-45] Se acumulan cinco oxímoros, todo ellos referidos al oro: "dulce desvelo", "peligro precioso", "rubia tierra", "pobreza disfrazada" y "ponzoña dorada". Expresiones parecidas, referidas siempre a la riqueza, son frecuentes en otras obras de Quevedo: "descolorida paz, preciosa guerra, / veneno de la aurora y el poniente" (núm. 117); "pobreza acreditada, fatiga dulce, inquietud preciosa" (núm. 43); "invidia de buen color y miseria preciosa" 99 . La frase "peligro precioso", también empleada por Quevedo en otros poemas ("a ser peligro tan precioso viene", núm. 72; "los peligros preciosos del oriente", núm. 12, v. 90), procede de Boecio: "Heu primus quis fuit ille, / auri qui pondera tecti / gemmasque latere volentes / pretiosa pericula fodit?"100. La traducción de fray Alberto de Aguayo dice así: "¡Oh quién fueron los primeros / tan sagaces cobdiciosos / que buscaron los mineros, / que acuñaron los dineros, / peligros atán preciosos!".

98 Cf. R. LAPESA, op. cit., p. 100; AnTONio Villanova, Las fuentes y los temas del "Po" lifemo" de Góngora, CSIC, Madrid, 1957, pp. 195-204.

99 F. De Quevedo, Hora de todos, Obras completas en prosa (OCP), Castalia, Madrid, t. 1, p. 755 (en prensa).

100 Consolación de la filosofía, lib. II, poema V, w. 27-30. 
Ay, no lleves contigo

metal de la quietud siempre enemigo;

que aun la Naturaleza, viendo que era

tan contrario a la santa paz primera,

los montes le echó encima;

sus caminos borró con altos mares.

\section{[v. 49] "santa paz primera": la paz que reinaba en la Edad de Oro.}

[v. 50] “a quien le estima": a quien lo busca, a quien lo desea.

[vv. 48-53] La idea de que la Naturaleza escondió de los hombres los metales, poniéndolos bajo la tierra y alejándolos mediante los mares, es de origen clásico. Según Ovidio, la edad de hierro se caracteriza porque el hombre no pidió a la tierra solamente su alimento, "sed itum est in viscera terrae, / quasque recondiderat Stygiisque admoverat umbris, / effodiuntur opes, inritamenta malorum"101. La misma idea aparece reiteradamente en Séneca: "Quidquid nobis bono futurum erat, deus et parens noster in proximo posuit; non expectavit inquisitionem nostram et ultro dedit. Nocitura altissime pressit. Nihil nisi de nobis queri possumus; ea, quibus periremus, nolente rerum natura et abscondente protulimus"102; "Illa nos peremunt, illa nos ad inferos agunt, quae occultavit atque demersit, illa, quae non nascuntur repente... Quam innocens, quam beata, inmo vero etiam delicata esset vita, si nihil aliunde quam supra terras concupisceret, breviterque, nisi quod secum est!"l03; "His omne metallum: / electri gemino pallent de semine venae, / atque atros chalybis fetus humus horrida nutrit. / Sed scelerum causas operit deus"104. "[Dios] nos provee de

101 Ovidio, Metamorfosis, I, 138-140. “...sino que se penetró en las entrañas de la tierra y se excavaron los tesoros, estímulo de la depravación, que ella había escondido llevándolos:junto a la sombra de la Estigia".

102 SÉnecA, Cartas a Lucilio, CX, 10. Doy la traducción que de esta epístola hizo el propio Quevedo: "Cualquier cosa que nos había de ser bien, Dios y Padre nuestro nos la puso cerca. No aguardó nuestra solicitud, delante nos la puso; los daños hondamente nos los sepultó. De nada sino de nosotros podemos quejarnos; sacaremos de lo más hondo aquellas cosas con que hayamos de perecer, no sólo negándonoslas la naturaleza, sino resistiéndonoslas" (Obras en prosa, Aguilar, Madrid, 1974, p. 1918).

${ }^{103}$ Plinio, Historia natural, XXXIII, 1. "Las cosas que [la tierra] ocultó y hundió, aquellas que no brotan rápidamente, son las que nos destruyen y nos degradan... Guán inocente, cuán feliz, cuán agradable incluso sería la vida si no deseara más que lo que está en la superficie de la tierra, es decir, aquello que está al alcance de su mano".

${ }^{104}$ Silio ItTálıco, I, 228-231. "En estos lugares se encuentran todos los metales; las venas del electro palidecen a causa de su doble origen y el terreno escabroso nutre el fruto del cruel hierro; pero el cielo entierra la causa del crimen". 
lo necesario... Ahora bien, lo que no es estrictamente necesario, lo ha escondido en las profundidades de la tierra y del agua"105. Cf. Juan de Jáuregui, "Al oro": "Sabia naturaleza... yo la sagaz destreza / alabo de tus manos, / que en viva peña, en áspera montaña / los metales avaros escondiste"106; Francisco de Rioja, "A la riqueza": "No sin causa los dioses te ascondieron / en las entrañas de la tierra dura"107; "No acaso dio la Naturaleza en todas partes tan pródigamente los frutos y celó en los profundos senos de la tierra la plata y el oro. Con advertencia hizo comunes aquellos y los puso sobre la tierra... y encerró estos metales para que costase trabajo el hallarlos"108; "Escondió próvidamente la Naturaleza la plata y el oro en las entrañas de la tierra, como a metales perturbadores de nuestro sosiego, y con gran providencia los retiró a regiones más remotas, poniéndoles por foso el inmenso mar Océa no y por muros altas y peñascosas montañas"109. Tanto en la poesía como en la prosa de Quevedo aparece reiteradamente esta idea: "Distantes orillas, a que fue divorcio con rabiosos golfos el Océano"110; "[los metales] escondió con tanto cuidado la naturaleza, que los cargó los montes encima, borrando sus caminos con los golfos y apartándolo de nuestra codicia con el divorcio de todo el Océano"111.

[v. 53] La idea de que los mares están para separar a los pueblos y poner freno a la codicia de los hombres aparece varias veces en Quevedo: “A robar oro y a inquietar los pueblos apartados, a quien Dios puso como defensa a nuestra ambición mares en medio y montañas ásperas"112; "La agua con que derramada en mares le fue divorcio de las naciones, en cuyos montes estaba enterrado el precioso peligro de su vida, el veneno resplandeciente, la tierra de mejor color y peores hechos"113; "Derramado y sonoro el Oceano / era divorcio de las rubias minas / que usurparon la paz del pecho humano"114; cf: también: "provincias tan remotas, no acaso retiradas de la Naturaleza con montes interpuestos de olas" 115.

105 Clemente de Alejandría, El Pedagogo, trad. J. Sariol Díaz, Gredos, Madrid, 1990, p. 251.

106 Obras, t. 1, p. 37.

107 Poesía, p. 172.

108 Diego SaAvedra Fajardo, Empresas políticas, ed. F. J. Díaz de Revenga, Planeta, Barcelona, 1988, p. 485.

109 D. SaAvedra Fajardo, República literaria, ed. J. C. de Torres, Plaza y Janés, Barcelona, 1985, p. 71.

110 Obras en prosa, p. 1549.

111 Providencia de Dios, en Obras en prosa, p. 1591.

112 Sueños, en $O C P$, t. 1, p. 301.

113 F. DE Quevedo, Virtud militante, ed. A. Rey, Universidad de Santiago de Compostela, 1985, p. 124.

114 "Epístola satírica y censoria", vv. 67-69.

115 D. SaAvedra Fajardo, Empresas políticas, p. 486. 
Doy que a tu patria vuelvas al instante que el occidente dejas saqueado, y que de él vas triunfante; doy que el mar sosegado debajo del precioso peso gime cuando sus fuerzas líquidas oprime la soberbia y el peso del dinero; doy que te sirva el viento lisonjero, si su furor recelas; doy que respete al cáñamo y las velas; $y$, porque tu camino esté más cierto, bien que imposible sea, doy que te salga a recibir el puerto cuando tu pobre casa ya se vea.

Este pasaje está constituido por una serie de cinco frases introducidas por "doy que", expresión empleada aquí con un sentido concesivo. El autor admite la posibilidad de que el interlocutor salga con bien de todos los peligros de la navegación cuando vuelva a casa cargado de riquezas. Hay un poema de Francisco de Rioja, quizá posterior a éste de Quevedo, donde se encuentran unos versos muy semejantes: "Mas doy que vuelen vuestras naves solas, / no con alas de lino, el ponto vario, / y que lleguen al puerto, y las arenas / ya pisemos de playas peregrinas; / y doy que luego las profundas minas, / no como siempre avaras, el tesoro / nos ofrezcan que asconden en sus venas..."116.

[v. 55] "que el occidente dejas saqueado": que has conseguido grandes riquezas en América.

[w. 58-60] "Admito que consigas traer tus riquezas sin sufrir ninguna tempestad". La idea de que las naves son un peso que "oprime" el mar y que le hace "gemir" es un lugar común en la poesía áurea. Ya en la Aquileida de Estacio se dice: "Video iam mille carinis / Ionium Aegaeumque premi" 117 . El motivo aparece con frecuencia en la poesía posterior: "Geme il vicino mar sotto l'incarco / de l'alte navi"118; "Del más gallardo y más vistoso extremo / de cuantos las espaldas de Neptuno / oprimieronjjamás"119; "ya siente el mar undísono la carga, / y del peso parece que suspira" 120 ; "Ya sin temor alguno / de verse el

116 F. DE Rioja, Poesía, p. 184, véase, también, Versos, ed. G. Chiappini, D'Anna, Firenze, 1975, pp. 463-465. Véanse, AlFonso REY, Quevedo y la poesia moral española, Castalia, Madrid, 1995, pp. 222 ss., y Manuel Ángel Candelas Colodrón, Las silvas de Quevedo, Universidad de Vigo, 1997, p. 132.

117 1, w. 34-35. "Veo ya al Jonio y al Egeo oprimidos por mil naves".

${ }^{118}$ T. TAsso, Gerusalemmeliberata, ed.M. Guglielminetti, Garzanti, Milano, 1982,1,79.

119 Miguel de Cervantes, Viaje del Parnaso, ed. V. Gaos, Castalia, Madrid, 1973, I, vv. 154-156.

120 L. DE VEGA, "La Circe", Obras poéticas, p. 1032. 
tridentífero Neptuno / oprimido del peso de las naves"121; "Las naves indias... tu pecho opriman"122; "A toda diligencia aprestó un barco / que hace gemir las aguas con su peso"123; "ni el oprimir tus olas / las naves y galeras españolas"124; "No cantara Marón que el mar Egeo / gimió oprimido con la griega armada"125; "Malhaya quien del Oceano fiero / la corva espalda con errante prora / oprimir supo"126; "[E] hombre], con un frágil leño, oprime la soberbia del mar"127. La imagen aparece con frecuencia en la poesía de Quevedo: "y el que enseñó a su espalda ondosa y fuerte / a que sufriese el peso de un madero" (núm. 134); "da ley al mundo y peso al Oceano" (núm. 137, v. 4); "Ansí, sagrado mar, nunca te oprima / menos ilustre peso" (núm. 231).

[v. 61-62] Supongamos que el viento, a pesar del temor que produce su furia ("si su furor recelas", con sentido concesivo), impulse suavemente tus navios sin peligro, por lo tanto "sirviéndote", obedecien do a tus deseos, y sin producir daño alguno, es decir, respetando a las velas y al cáñamo del que están hechas las cuerdas del barco. "Lisonjero" además de en su acepción de "adulador", "se usa también como adje tivo aplicándole a cualquier cosa que deleita o agrada" (Dicc. Aut.).

[vv. 66-67] Que tomes tierra con tanta facilidad y suavidad que es como si el puerto "te saliera a recibir".

Rico, dime si acaso en tus montones de oro

70 tropezará la muerte o tendrá el paso; si añidirá a tu vida tu tesoro un año, un mes, un día, un hora, un punto. No es poderoso a tanto el mundo junto. Pues si este don tan pobre te es negado, ¿de qué esperanzas vives arrastrado? Deja, no caves más, el metal fiero; ve que sacas consuelo a tu heredero; ve que buscas riquezas, si se advierte, para premiar deseos de tu muerte. Sacas, ay, un tirano de tu sueño, un polvo que después será tu dueño;

${ }^{121}$ L. DE VEGA, "El Siglo de Oro", Rimas humanas..., p. 795, vv. 28-30.

122 L. DE VEGA, Rimas, I, p. 349.

123 B. de Balbuena, El Bernardo, p. 328.

124 Andrés Fernầndez de Andrada, Epistola moral a Fabio y otros escritos, ed. D. Alonso, Crítica, Barcelona, 1993, p. 87.

${ }^{125}$ Luis Martín de la Plaza, Poesías completas, Diputación Provincial de Málaga, 1995 , p. 250.

126 F. Trillo y Figueroa, Obras, p. 468.

${ }^{127}$ F. SAAVEDRA Fajardo, Empresas politicas, p. 577. 
y en cada grano sacas dos millones de envidiosos, cuidados y ladrones. Déjale, oh Leiva, si es que te aconsejas con la santa verdad honesta y pura, pues él te ha de dejar si no le dejas, o te lo ha de quitar la muerte dura.

[vv. 68-72] "Dime si la riqueza te servirá para evitar la muerte o para prolongarte siquiera un instante la vida”. M. del Carmen Rocha ${ }^{128}$ señala como precedente de estos versos la oda XXIV del libro III de Horacio y también un pasaje de la traducción de Anacreonte del propio Quevedo: "Si grande copia de oro recogida / pudiera, amigos, alargar la vida, / no soy tan necio yo que no buscara / el oro donde quiera que se hallara... / Mas si es trabajo vano / querer no ser mortal quien es humano, / ¿para qué me fatigo?"129. Aunque a veces Quevedo traduce con ciertas libertades, la idea es la misma que se encuentra en el texto original griego. Pero además de estos recuerdos clásicos, parece haber también una reminiscencia de los evangelios: "¿Y quién de vosotros con acongojarse puede añadir un codo a la duración de su vida?" (Lucas, 12, 25).

[v. 71] "añidirá": por "añadirá". La variante no es infrecuente en el siglo XVII.

[v. 77] La riquezas sólo servirán para hacer felices a tus herederos.

[v. 79] Las riquezas serán el premio que tendrán tus herederos por haber deseado fervientemente tu muerte. Compárese: "[el avaro] junta en sus tesoros deseos de su muerte"130; "Quien tiene lo que ha de dejar a otro, le.justifica, o por lo menos le ocasiona deseos de que se lo deje"131. Encontramos el mismo tema en otros poetas: "Tal hay que anhela al oro forastero... / Para premiar deseos de heredero / turba la paz al seno de los montes"132; "Tí al heredero, que tu muerte llama / y en ruegos su presteza solicita, / cuanto pudieres quita"133. El que la idea aparezca en tres escritores estrictamente coetáneos me hace suponer que hay una fuente común que desconozco.

[v. 80] Las riquezas sólo sirven para crear inquietud e impedir el sueño apacible. Son, pues, "un tirano de tu sueño".

\footnotetext{
128 Ed. cit. a Cinco silvas, p. 163.

129 Anacreón castellano, núm. XXIII, OP, IV, p. 296.

$1^{30}$ F. DE QUeVEDo, Virtud militante, p. 170.

131 Marco Bruto, en $O C P$, p. 937.

132 P. De Espinosa, Poesias completas, p. 143.

${ }^{133}$ L. Martín de la Plaza, op. cit., p. 250.
} 
[v. 81] Varias veces llama Quevedo "polvo" al oro, se supone que para destacar el poco valor que tienen en realidad las riquezas. En otro poema, hablando también del oro, dice que: "a ser peligro tan precioso viene / polvo que, en vez de enriquecer, ultraja" (núm. 80). En otros pasajes de su obra se encuentran expresiones parecidas, pero de sentido más oscuro: "hurtado para siempre a la grandeza, / al envidioso polvo cortesano" (núm. 12); "escondido en polvo cortesano" (núm. 80); "la riqueza molesta y espiada, / el polvo cortesano" (núm. 145 , vv. 300-301). Hay un lugar de su prosa que quizá aclare la metáfora del oro como polvo: "Repasemos los martirios que por nuestra codicia padece el oro... Persiguele el hierro, rompiendo por las entrañas de su madre; sacándole de sus venas hechos polvos y despedazado, le amasan con azogue" (OCP, p. 1590). Fray Diego de Hojeda pone en boca de Judas estas palabras: “ ¿Por esta tierra y polvo congelado / vendí yo, miserable, al rey del cielo?... Porque vendí al Señor... / por hambre de estos polvos avarienta"134.

[v. 83] "dos millones / de envidiosos, cuidados y ladrones": pues la riqueza produce envidia en los otros y preocupaciones ("cuidados") en el propietario, además de atraer a los ladrones.

Enrique Moreno Castillo

${ }^{134}$ Fray Diego de Hojeda, La Christiada, ed. Sister M. H. P. Corcoran, The Catholic University of America, Washington, 1935, p. 260. 